\title{
METALS IN MEDICINE WORKSHOP
}

A workshop covering topics related to the use of Metal Complexes in Medicine will be held as an applications day of the

IXth International Conference of the Chemistry and Organometallic Chemistry of Germanium, Tin, and Lead

Location: World Congress Centre, Melbourne

Date: Wednesday September 23rd, 1998

Speakers who have agreed to participate are:

Plenary lecturer: Jan Reedijk (Leiden University)

Contributing Speakers: Sue Berners-Price (Griffith University), Trevor Hambley (The University of Sydney), Margaret Harding (The University of Sydney), V.G. Kumar Das (Universiti Malaysia), Edmunds Lukevics (Latvian Institute of Organic Synthesis), Michael Millward (Peter MacCallum Cancer Institute), Valery Petrosyan (Lomonosov University), Lou Rendina (The University of Adelaide), Youn Soo Sohn (Korea Institute of Science and Technology), Dick de Vos (Pharmachemie BV, Haarlem) and Lorraine Webster (Peter MacCallum Cancer Institute)

\section{Tentative Program:}

$\begin{array}{ll}\text { 9:30 } & \text { Welcome } \\ 9: 35 & \text { Plenary lecture } \\ \text { 10:30 } & \text { Catered morning tea } \\ \text { 11:00 } & \text { Lectures } \\ \text { 12:20 } & \text { Catered lunch } \\ 1: 30 & \text { Lectures } \\ 3: 00 & \text { Catered afternoon tea } \\ 3: 30 & \text { Lectures } \\ 4: 10 & \text { Poster session with catered refreshments } \\ \text { 6:00 } & \text { Close }\end{array}$


Proceedings: The proceedings of the Metals in Medicine workshop will be published in Metal-Based Drugs. All participants (oral and poster presentations) are invited to contribute to the dedicated issue(s) of Metal-Based Drugs. The proceedings will be distributed at the Metals in Medicine workshop and hence, strict deadlines for submission of articles/abstracts will be adhered to.

All contributions should be sent to

Dr ERT Tiekink

Department of Chemistry,

The University of Adelaide, AUSTRALIA 5005

etiekink@chemistry.adelaide.edu.au

The deadline for all contributions to be included in the Metals in Medicine proceedings is June 30th, 1998.

Instructions for authors are attached.

All papers will be subject to the normal refereeing procedures. Submissions should be submitted electronically wherever possible. Reprints will be distributed free of charge to the principal author.

Participants who wish to present a poster are advised that the poster space is $1 \mathrm{~m}$ wide and $1.5 \mathrm{~m}$ high.

\section{Registration:}

The all inclusive (morning/afternoon teas, lunch, poster session and proceedings) cost for the Metals in Medicine workshop will be \$AUD 150 (\$AUD 90 for students, unemployed, retired participants). A registration form is attached. Other details (i.e. about Melbourne, accommodation, etc) may be downloaded from our website or obtained from Dr Tiekink at the above address.

\section{Web site:}

http://www.science.adelaide.edu.au/chemist/conferences/ICCOCGTL9/mmw.htm 